\title{
Long non-coding RNA MEG3 inhibits the proliferation of cervical carcinoma cells through the induction of cell cycle arrest and apoptosis
}

\author{
R. QIN ${ }^{1, \star}$, Z. CHEN ${ }^{2}$, Y. DING 3 , J. HAO ${ }^{4}$, J. HU ${ }^{5}, \mathrm{~F}_{\text {GUO }}{ }^{1}$ \\ ${ }^{1}$ Department of Gynecology and Obstetrics; ${ }^{2}$ Department of Cardiovascular Medicine; ${ }^{3}$ Department of Pharmacy; ${ }^{4}$ Department of Infection \\ Diseases; ${ }^{5}$ Intensive Care Unit, The First Affiliated Hospital, Xinxiang Medical University, Henan, China
}

*Correspondence: qry201274@126.com

Received November 22, 2012/ Accepted February 18, 2013

\begin{abstract}
Cervical cancer remains an important public health problem worldwide. New and effective therapeutic strategies targeting cervical cancer are urgently needed. Long non-coding RNAs (lncRNAs) are newly identified regulators in tumorigenesis and tumor progression. To investigate the role of lncRNA MEG3 in the development of cervical cancer, we examined MEG3 expression in 18 pairs of cervical cancer and matched adjacent non-neoplastic tissues. Real-time quantitative RT-PCR (qRT-PCR) results showed high expression levels of MEG3 in non-neoplastic tissues, but markedly lower levels in cancer tissues. We further investigated whether the restoration of MEG3 expression might affect the proliferation of cervical carcinoma cells. Ectopic expression of MEG3 inhibited the proliferation of human cervical carcinoma cells HeLa and C-33A in vitro. On the other hand, knockdown of MEG3 promoted the growth of well-differentiated cervical carcinoma HCC94 cells. Further investigation into the mechanisms responsible for the growth inhibitory effects revealed that overexpression of MEG3 resulted in the induction of G2/M cell cycle arrest and apoptosis. These results identified an important role of MEG3 in the molecular etiology of cervical cancer and implicated the potential application of MEG3 in cervical cancer therapy.
\end{abstract}

Key words: cervical cancer, long non-coding RNAs; MEG3, apoptosis

Although the incidence of cervical cancer has been greatly reduced with the application of pap smear screening, cervical cancer is still the third most commonly diagnosed cancer in women worldwide, with estimated 529,800 new cases diagnosed annually [1]. Therefore, new and effective therapeutic strategies for cervical cancer are urgently needed.

Noncoding RNAs (ncRNAs) are newly discovered regulators of diverse biological functions. In cancer, ncRNAs have been shown to have both supportive and inhibitory effects in tumor development $[2,3]$. ncRNAs can be grouped into two major classes based on the sizes of their transcripts: small ncRNAs (<200 bp) and long ncRNAs (lncRNAs) (>= $200 \mathrm{bp}$ ) $[4,5]$. Small ncRNAs comprise a broad range of RNA species, and many of them are associated with 5' or 3' regions of genes. microRNA is one of the most important small ncRNAs that have been documented to play important roles in cancer development [6-8].

Recent studies identified an important role for lncRNAs in tumor progression [9]. LncRNAs, ranging from $200 \mathrm{nu}-$ cleotides to over $10 \mathrm{~kb}$, are abundantly transcribed by the mammalian genome $[10,11]$. Increasing evidence support the association of aberrant lncRNA expression with human cancers. As lncRNAs are emerging as critical components of the cancer transcriptome, it is reasonable to anticipate that lncRNAs may contribute to the tumorigenesis and progression of cervical cancer. Gibb EA et al [12] provided the first lncRNA expression profile in the human cervical intraepithelial neoplasia (CIN) transcriptome and demonstrated aberrant lncRNA expression in early-stage neoplasia.

Maternally expressed gene 3 (MEG3), an imprinted gene, is a tumor suppressor gene located in chromosome $14 \mathrm{q} 32$ [13]. The potential functions of MEG3 have been studied in a number of cancer types. MEG3 is down-regulated in several cancer types. In addition, overexpression of MEG3 inhibits pituitary tumor cell proliferation, suggesting that MEG3 is a potential tumor suppressor gene [14]. Likewise, re-expression of MEG3 inhibits the proliferation of tumor cells in vitro in glioma [15] and meningioma [16]. Further, 
MEG3 is reported to be dysregulated in certain tumors, such as hepatocellular carcinoma [17], Wilms tumors [18], and multiple myeloma [19]. However, the role of MEG3 in tumorigenesis and progression of cervical cancer remains unknown.

In this study, we examined the expression of lncRNA MEG3 in 18 pairs of cervical cancer and matched nonneoplastic tissues using real-time quantitative RT-PCR (qRT-PCR). Moreover, we investigated the impact of ectopic expression of MEG3 in proliferation, cell cycle progression and apoptosis in vitro in human cervical carcinoma cells HeLa and C-33A.

\section{Materials and methods}

Tissue samples. Eighteen pairs of primary cervical cancer and matched adjacent non-neoplastic tissues were obtained from the Department of Gynecology and Obstetrics in the First Affiliated Hospital of Xinxiang Medical University. The study protocol was approved by the Institutional Review Board of Xinxiang Medical University. Written informed consent was obtained from all patients enrolled in the study. Tissues were cut into pieces smaller than $0.5 \mathrm{~cm}$ in any single dimension and immediately immersed into $2 \mathrm{ml}$ RNAlater solution (Ambion, Foster City, CA). Tissue samples were stored in liquid nitrogen until use. Tissue sections from each sample were reviewed and classified by a pathologist.

Quantitative reverse transcriptase PCR (qRT-PCR). Total RNA was isolated from cervical cancer and matched non-tumor tissues using the RNeasy kit (Qiagen, Grand Island, NY) according to manufacturer's instructions. Reverse transcription reactions were carried out with $1 \mathrm{mg}$ total RNA using the PrimeScript ${ }^{\oplus}$ RT reagent kit (TaKaRa BIO, Shiga, Japan). Random hexamer primers were used in the RT reactions. Real-time PCR was performed on a Bio-Rad CFX-96 real-time PCR system (Bio-Rad, Hercules, CA) using SYBR ${ }^{\curvearrowleft}$ Premix DimerEraser kit (TaKaRa, Shiga, Japan) following the manufacturer's instructions. MEG3 primer sequences were obtained from previous publication [15] as following: Sense, CTGCCCATCTACACCTCACG;

Antisense, CTCTCCGCCGTCTGCGCTAGGGGCT. GAPDH was used as a housekeeper gene for the qRT-PCR reactions. Each test was done in triple replication and the 2$\Delta \triangle \mathrm{Ct}$ method was used to calculate the expression of lncRNA MEG3 in tissue samples.

Cell culture. Human cervical carcinoma cells lines HeLa, C-33A and HCC94 (well-differentiated) were obtained from the Cell Bank of the Chinese Academy of Sciences and maintained in modified Eagle's media (MEM) containing $10 \%$ fetal bovine serum (FBS) at $37^{\circ} \mathrm{C}$ in a $5 \% \mathrm{CO}_{2}$ atmosphere.

MTS cell growth assay. Plasmid pEGFP-MEG3 was constructed by subcloning MEG3 cDNA in an EcoRIBamHI fragment into the pEGFP vector. HeLa or C-33A cells were transiently transfected with pEGFP-MEG3 using Lipo- fectamine 2000 (Life technologies, Carlsbad, CA). These cells were reported to have high transfection efficiencies [20]. Cell proliferation was evaluated using colorimetric MTS assay (Promega, Madison, WI) following the manufacturer's protocol. MTS assay measures the restoration of 3-(4,5-dimethylthiazol-2-yl)-5-(3-carboxymethoxyphenyl)2-(4-sulfophenyl)-2H-tetrazolium (MTS) to formazan by metabolically active cells.

siRNA transfection and MTS cell growth assay. Well-differentiated cervical carcinoma HCC94 cells were grown in 24 -well culture plates to $80-90 \%$ confluence overnight and then transfected with $25 \mathrm{nM}$ non-targeting siRNA control, or synthetic siRNAs against MEG3 (Guangzhou RiboBio Co., Ltd.) for $48 \mathrm{~h}$ using Lipofectamine ${ }^{\mathrm{TM}}$ transfection reagent (Invitrogen) following the manufacturer's protocol. Following transfection, the cells were harvested and MEG3 knockdown was confirmed by qRT-PCR. HCC94 cells were transiently transfected with siRNA-MEG3 or control non-targeting siRNA for 24 to $72 \mathrm{~h}$, and cell proliferation was evaluated by MTS cell growth assay as described above.

Cell cycle analysis. HeLa or C-33A cells $\left(5 \times 10^{5}\right)$ were plated in $60 \mathrm{~mm}$ dishes overnight. The cells were then transiently transfected with pEGFP-MEG3 or control vector for $48 \mathrm{~h}$. Adherent cells were trypsinized and resuspended in cold PBS. Three volumes of cold $70 \%$ ethanol were added in a dropwise manner while vortexing. Cell suspensions were fixed for $24 \mathrm{~h}$ at $-20^{\circ} \mathrm{C}$, washed twice with cold PBS. Cells were resuspended in $100 \mu \mathrm{g} / \mathrm{ml}$ RNase A in $100 \mu \mathrm{l}$ PBS. Five min later, $50 \mu \mathrm{g} / \mathrm{ml}$ propidium iodide in $400 \mu \mathrm{l}$ PBS was added. Cell cycle progression was analyzed using a Becton Dickinson FACScan flow cytometer. Cell cycle analysis was performed using the FCS Express 4 software (De Novo Software, Los Angeles, CA).

Apoptosis assay. HeLa or C-33A cells $\left(5 \times 10^{5}\right)$ were plated in $60 \mathrm{~mm}$ dishes overnight. The cells were then transiently transfected with pEGFP-MEG3 or control vector for $48 \mathrm{~h}$. Cells were collected by trypsinization, washed twice with cold PBS and then resuspended in $1 \times$ Binding buffer at a concentration of $1 \times 10^{6} \mathrm{cells} / \mathrm{ml} .100 \mu \mathrm{l}$ cell suspension was transferred to a $5 \mathrm{ml}$ tube and stained with annexin $\mathrm{V}$ and 7-aminoactinomycin D (7-AAD) (BD Biosciences, San Diego, CA) according to the manufacturer's protocol. Stained cells were immediately analyzed using a BD FACScan flow cytometer. Data analysis were performed using the FCS Express 4 software.

Western blot analysis. The cells were transfected with pEGFP-MEG3 or control vector for $48 \mathrm{~h}$, and immediately lysed in RIPA buffer ( $10 \mathrm{~mm}$ Tris, pH 7.4, $150 \mathrm{~mm} \mathrm{NaCl}, 5 \mathrm{~mm}$ EDTA, $8 \%$ glycerol, $1 \%$ Triton X-100, $0.1 \%$ SDS, $0.5 \%$ sodium deoxycholate, $10 \mathrm{~mm} \mathrm{Na} 3 \mathrm{VO} 4,1 \mathrm{~mm}$ sodium fluoride, and Complete Protease Inhibitor Mixture (Roche Diagnostics)). $40 \mu \mathrm{g}$ of total protein per sample was separated by SDS-PAGE, blotted onto polyvinylidene fluoride membranes that were blocked for $1 \mathrm{~h}$ at room temperature with $5 \%$ nonfat dry milk in TBS containing $0.05 \%$ Tween 20 . The membranes 
were then incubated overnight at $4^{\circ} \mathrm{C}$ in nonfat dry milk in TBS containing $0.05 \%$ Tween 20 with the indicated primary antibodies. Membranes were washed in nonfat dry milk in TBS containing $0.05 \%$ Tween 20 and incubated with antirabbit $(1: 1,000)$ or anti-mouse $(1: 1,000)$ secondary antibody conjugated to horseradish peroxidase (Amersham Pharmacia
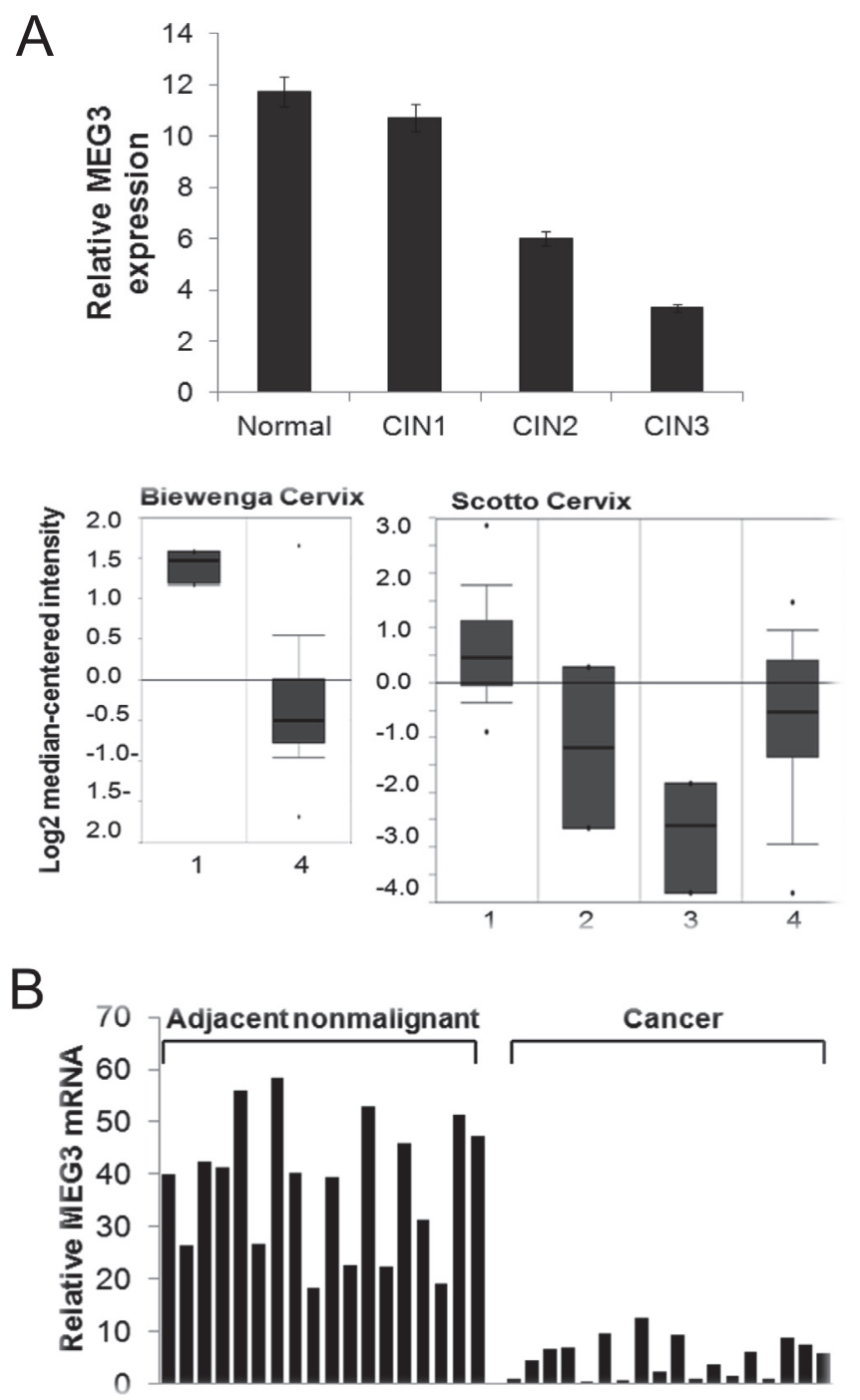

Figure 1. Down-regulation of lncRNA MEG3 expression in cervical cancer. A. Upper panel: Comparing the non-neoplastic cervix with CIN2 and CIN3 revealed differential IncRNA MEG3 expression. CIN: cervical intraepithelial neoplasia. CIN1: MILD, CIN2: moderate, CIN3: severe. Adapted from Gibb EA, et al. Aberrant Expression of Long Noncoding RNAs in Cervical Intraepithelial Neoplasia. Int J Gynecol Cancer 2012 Nov;22(9):1557-63. Lower panel: Oncomine study data shows lower MEG3 RNA expression levels in cervical cancer compared to normal. 1. normal, 2. cervical adenocarcinoma, 3. cervical cancer, 4 . cervical squamous cell carcinoma. Adapted from Biewenga (http://www.ncbi.nlm.nih.gov/geo/query/acc. cgi?acc=GSE7410) and Scotto's (http://www.ncbi.nlm.nih.gov/geo/query/ acc.cgi?acc=GSE9750) publication. B. Real-time $\mathrm{qRT}$-PCR was carried out on cervical cancers and their matched adjacent non-tumor tissue samples. Data were analyzed using the $2^{-\Delta \Delta \mathrm{Ct}}$ method.
Biotech, Piscataway, NJ). Visualization of the protein bands was done using the enhanced chemiluminescence plus kit as recommended by the manufacturer (Perkin-Elmer, Boston, MA). The following primary antibodies were obtained from Santa Cruz Biotechnology: p53 (sc-6243), p21 (sc-397), cyclin B1 (sc-245), Cdk1/Cdk2 Antibody (sc-53219), caspase 3 (sc7148), caspase 8 (sc- 56070), and actin (sc-8432).

Statistical analysis. Statistical significances between groups were determined by two-tailed Student's t-test. A p-value of < 0.05 was considered significant.

\section{Results}

Down-regulation of IncRNA MEG3 expression in cervical cancer. Obtained data revealed that lncRNA MEG3 was markedly down-regulated in moderate (CIN2) and severe (CIN3) histopathologic grades of CIN compare to non-neoplastic cervical tissues [12] (Fig. 1A, upper panel). MEG3 expression was reversely correlated with the severity of the tumor.

To further evaluate the clinical relevance of MEG3, expression of MEG3 in 18 pairs of cervical cancer and matched non-neoplastic tissues were analyzed by qRT-PCR. High expression levels of MEG3 were detected in non-neoplastic tissues, but markedly lower levels were identified in cancer tissues $(\mathrm{P}<0.01$, Fig. 1B).

To further confirm our finding that MEG3 is down-regulated in cervical cancer in comparison to non-tumor tissues, we analyzed published data on Oncomine Database and found increased expression of MEG3 in non-tumor cervial tissues compared with cervical cancers (Fig. 1A, lower panel). These results strongly indicate that MEG3 may contribute to tumorigenesis and malignant progression of cervical cancer.

MEG3 inhibits cell proliferation in human cervical carcinoma cell lines in vitro. Based on the observation that MEG3 expression level is high in normal cervical tissues but is low or undetectable in cervical cancer, we hypothesized that MEG3 is involved in the regulation of cervical cell proliferation. We tested this hypothesis in human cervical cancer cell lines HeLa and C-33A, which express very low levels of MEG3 [21]. HeLa or C-33A cells were transiently transfected with pEGFP-MEG3 or control vector, and cell viability was examined using the MTS cell growth assay. HeLa and C-33A cells were efficiently transfected with the pEGFP vector, as indicated by the green fluorescence introduced to the cells (data not shown). Over-expression of MEG3, as confirmed by qRT-PCR (Fig. 2A, left two panels), significantly (P < 0.05 ) inhibited the growth of HeLa or C-33A cells compared with control (Fig. 2B). To study whether down-regulation of MEG3 promotes cervical cancer cell proliferation, MEG3 was knocked down by siRNA in the well-differentiated HCC 94 cells which have high levels of endogenous MEG3(Fig. 2A, right panel). siRNA-MEG3 transfection increased the growth of HCC 94 cells $(\mathrm{P}<0.05$, Fig. 2B). These results indicate that MEG3 inhibits the proliferation of human cervical cancer cells in vitro. 

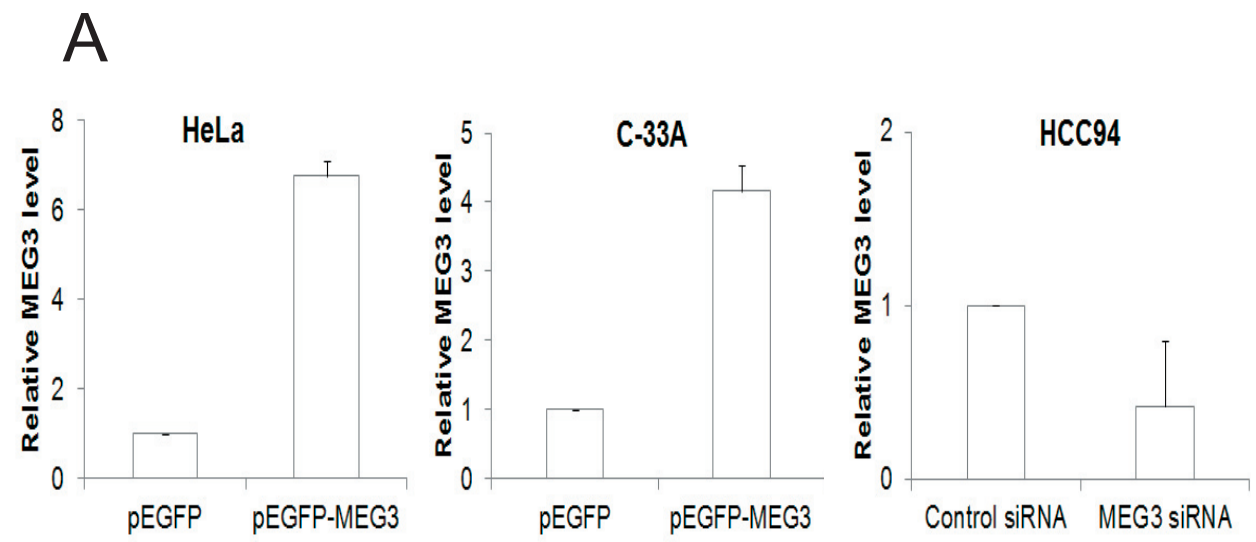

B
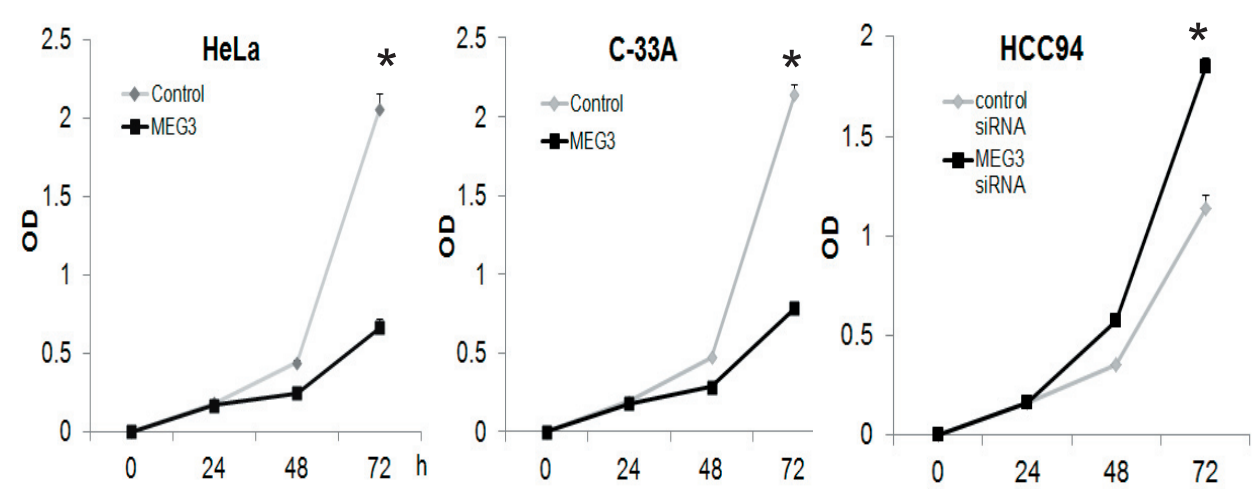

Figure 2. MEG3 inhibited the proliferation of human cervical carcinoma cells in vitro. A. HeLa and C-33A cells were transiently transfected with pEGFP-MEG3 or control vector for $48 \mathrm{~h}$. HCC94 cells were tranfected with MEG3 siRNA or control non-targeting siRNA for 48 h. qRTPCR analysis was performed to examine MEG3 RNA levels in HeLa, C-33A cells (two Left panels), and HCC94 cells (Right panel). B. HeLa and C-33A cells were transfected with pEGFP-MEG3 or pEGFP plasmid for $72 \mathrm{~h}$. HCC94 cells were transfected with MEG3 siRNA or control siRNA for $72 \mathrm{~h}$. Cell viability was measured using the MTS cell growth assay. The results shown are from three independent experiments and reported as the mean $\pm \mathrm{SD} .{ }^{*}, \mathrm{P}<0.05$.

MEG3 induces G2/M cell cycle arrest and apoptosis. Induction of cell cycle arrest is an important anti-proliferation mechanism. Next we investigated whether the growth inhibitory activity of MEG3 involved the control of cell cycle progression. Over-expression of MEG3 resulted in cell cycle arrest at G2/M phase in HeLa and C-33A cells (Fig. 3A). Microscopic observations revealed significant amount of cell death in addition to growth arrest following MEG3 transfection (data not shown). Therefore, we investigated whether MEG3 could also promote apoptotic cell death. HeLa and C-33A cells were transiently transfected with MEG3 for 48 $\mathrm{h}$ and apoptosis was analyzed by annexin V/7AAD staining. Over-expression of MEG3 induced both early (annexin $\mathrm{V}+$ /7-AAD-) and total (annexin $\mathrm{V}+$ ) apoptosis in HeLa and C-33A cells (Fig. 3B).

The $\mathrm{p} 53$ protein is a potent tumor suppressor and one of the important players in apoptosis signaling. LncRNAs have been shown to physically associate with $\mathrm{p} 53$, suggesting that lncRNAs may function through p53 pathway [22]. Therefore, we examined whether MEG3 regulates the expression of $\mathrm{p} 53$. Overexpression of MEG3 resulted in increased expression of p53 in Hela and C33A cells, as assessed by Western blot analysis (Fig. 4). Additionally, MEG3 increased the cleavage of p53 downstream target caspase 3 (Fig. 4). To elucidate the mechanisms for the G2/M phase arrest in MEG3-transfected cells, we investigated the expression of pivotal protein (cyclin B1 and CDK1) for G2/M transition [23]. Compared with control transfected cells, transfection with MEG3 resulted in decrease in cyclin B1 and CDK1 expression (Fig. 4). p21 is one of the p53 targets and acts as an inhibitor of G2/M transition [24]. As shown in Fig. 4, elevated p21 level was detected following MEG3 transfection. These results suggest that MEG3 may induce apoptosis through p53-mediated pathway. 


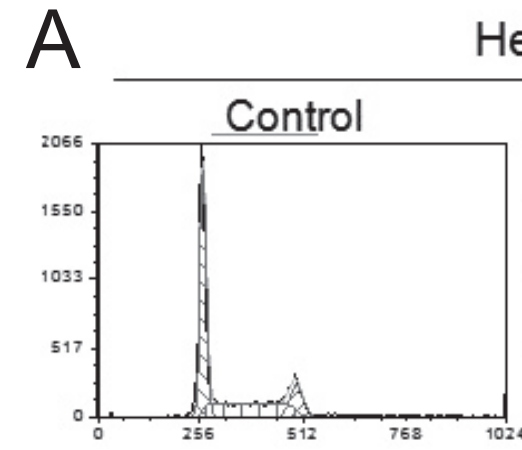

HeLa
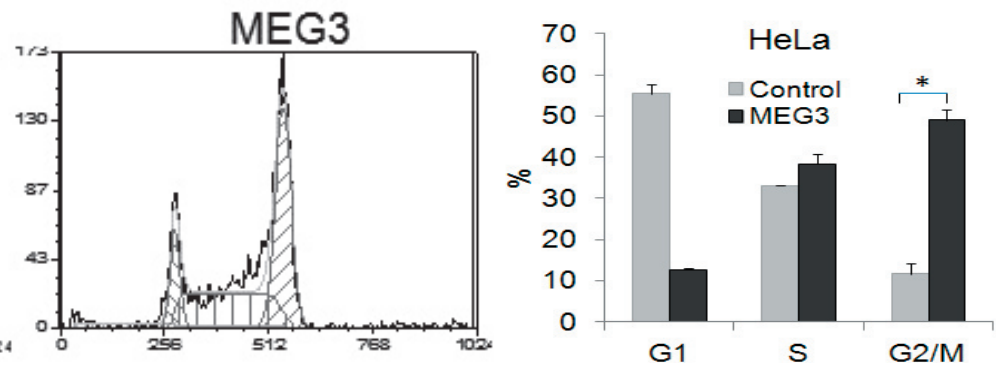

C-33A
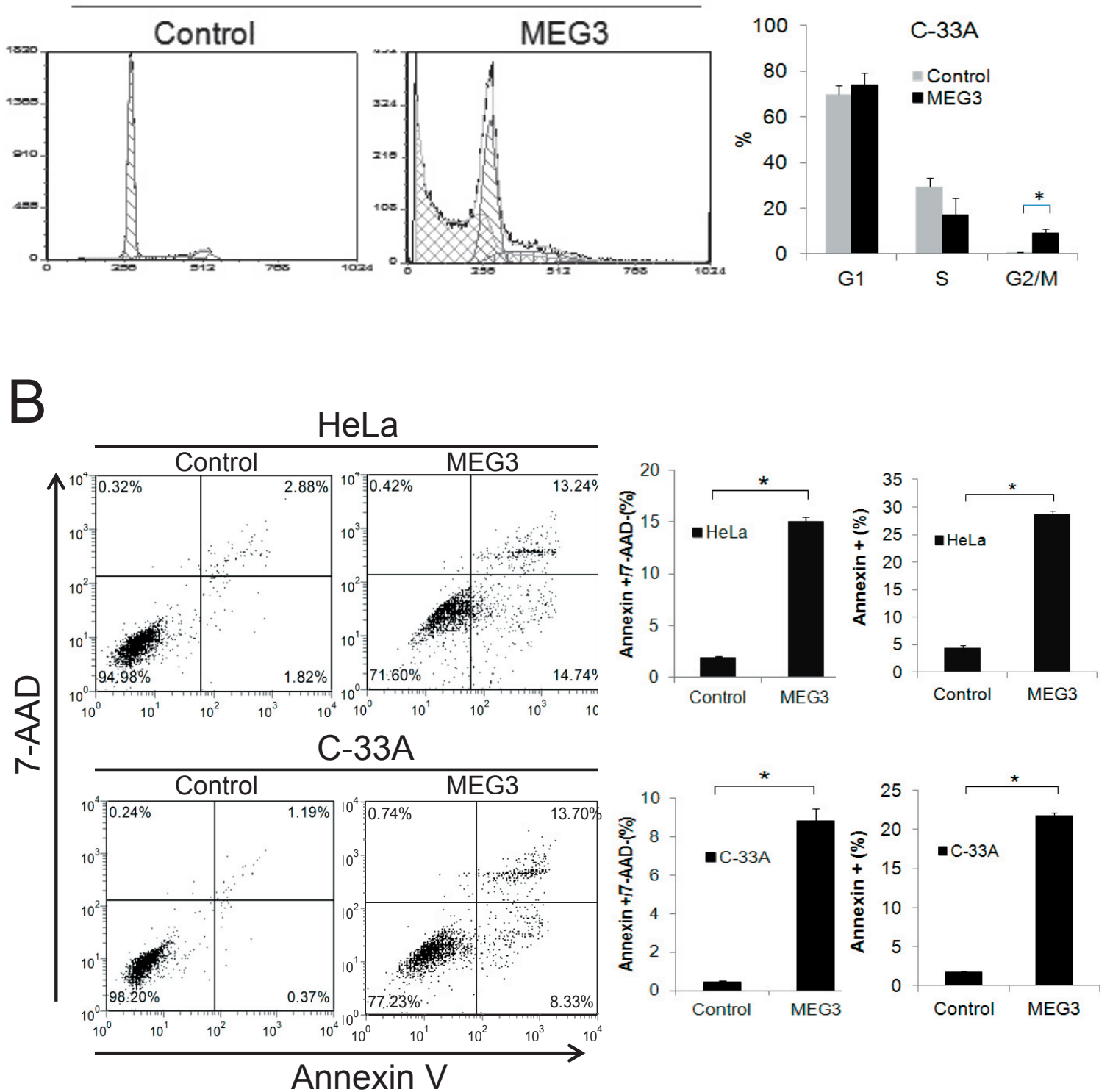

Figure 3. Over-expression of MEG3 induced G2/M arrest and apoptosis in cervical cancer cells. HeLa and C-33A cells were transiently transfected with pEGFP-MEG3 or control vector for $48 \mathrm{~h}$. A. Cell cycle analysis was performed by PI staining using flow cytometry. Representative histograms were presented (right panel). Results shown are representative of two independent experiments. ${ }^{*}, \mathbf{p}<0.05$. (left panel). B. Apoptosis was assessed by annexin V-FITC/7-AAD staining using flow cytometry. Representative histograms were presented (right panel). Results shown are representative of two independent experiments. ${ }^{*}, \mathrm{p}<0.01$. 


\section{Discussion}

LncRNAs belong to a newly identified class of RNA molecules which do not have protein-coding capacity [25]. LncRNAs control transcription of target genes, which indicates that the difference in IncRNA profiling between normal and cancer cells may not merely be the secondary effect of cancer transformation. Further, lncRNAs may be associated with cancer progression [26]. Thus, lncRNA expression profiles may be of important value in cancer diagnosis, prognosis and therapy.

In the present study, we evaluated the expression of lncRNA MEG3 in cervical cancer tissues and matched non-tumor tissues. We demonstrated that MEG3 expression was significantly $(\mathrm{P}<0.01)$ decreased in cervical cancer tissues compared with adjacent non-tumor tissues. In addition, the search of Oncomine database and published literature confirmed our findings that MEG3 is significantly down-regulated in cervical cancer compared with normal tissues. Further, ectopic expression of MEG3 inhibited the proliferation of human cervical carcinoma cells HeLa and C-33A in vitro. Knockdown of MEG3 promoted cell proliferation in well-differentiated cervical cancer HCC94 cells.

Braconi et al.[17] reported that ectopic expression of MEG3 induced apoptosis in hepatocellular cancer PRC/PRF/5 cells. MEG3-induced apoptosis was also observed in U251 and U87 glioma cells [15]. We further demonstrated that over-expression of MEG3 promoted apoptotic cell death and induced G2/M cell cycle arrest in HeLa and C-33A cells. We investigated the molecular mechanisms responsible for apoptosis and G2/M cell cycle arrest induced by MEG3 in Hela and C-33A cells. Western blot analysis results showed that CDK1 and cyclinB1 were down-regulated by the overexpression of MEG3, indicating that CDK1 and cyclinB1 may be involved in the induction of $\mathrm{G} 2 / \mathrm{M}$ cell cycle arrest by MEG3. In addition, MEG3 activates p53 and its downstream targets caspase 3 and p21. These results suggest that MEG3-mediated inhibition of tumor cell proliferation is due, at least in part, to the induction of G2/M cell cycle arrest and apoptosis through p53 and cyclin-CDK pathways.

The detailed mechanisms by which MEG3 inhibits tumor growth remain to be determined. Gordon FE et al [27] discovered increased expression of angiogenic genes in the brains of mouse MEG3-null embryos, suggesting that deletion of MEG3 promotes angiogenesis. It is well known that tumor growth and metastasis both require angiogenesis [28]. Therefore, enhanced angiogenesis may be another mechanism by which inactivation of MEG3 contributes to tumor development.

In conclusion, we demonstrate that MEG3 is significantly down-regulated in human cervical cancer tissues compared with matched non-neoplastic tissues. Over-expression of MEG3 inhibits human cervical cancer cell growth, which is associated with the induction of G2/M cell cycle arrest and apoptosis. These findings, together with findings by others, in-

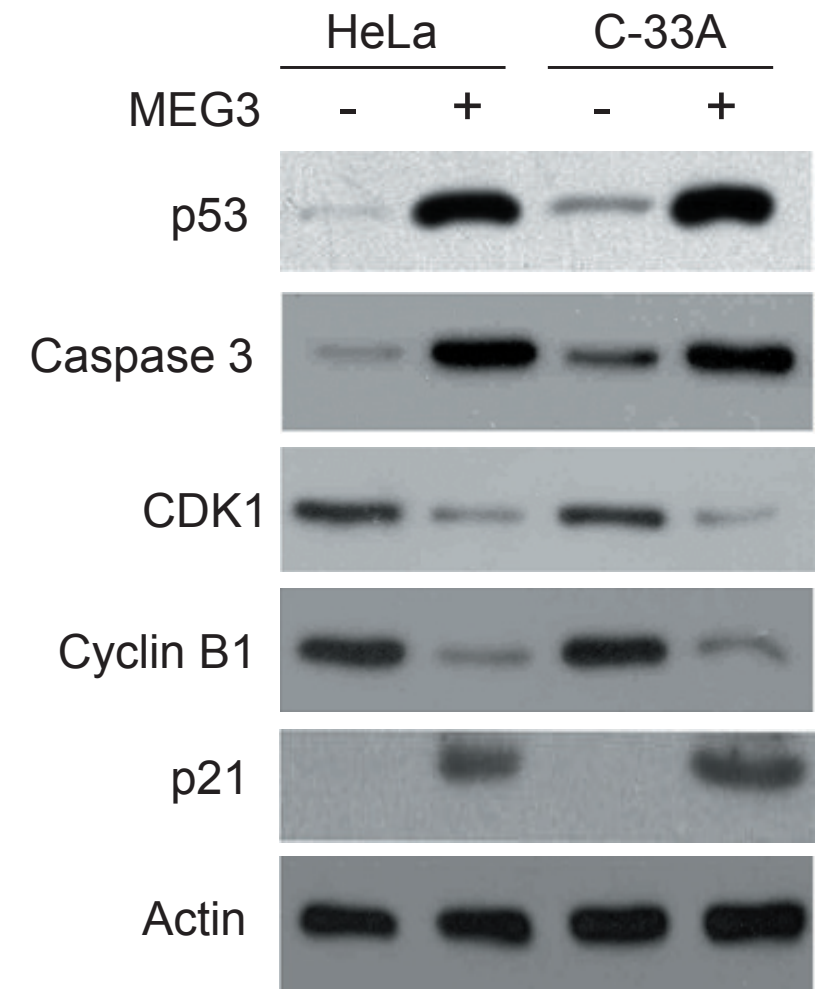

Figure 4. MEG3 regulates the expression of cell cycle and apoptosis related proteins in cervical cancer cells. HeLa and C-33A cells were transiently transfected with pEGFP-MEG3 or control vector for $48 \mathrm{~h}$. Cells were harvested, cell lysates prepared and then analyzed by Western blotting with antibodies to p53, caspase 3, p21, cyclinB1 and CDK1. Actin served as the loading control. Results were representative of three independent experiments.

dicate that MEG3 is a tumor suppressor and may be a potential target for cancer therapy.

Acknowledgements: This study was supported by the Research Grants of Henan Science and Technology Project (112102310271).

\section{References}

[1] JEMAL A, BRAY F, CENTER MM, FERLAY J, WARD E et al. Global cancer statistics. CA Cancer J Clin 2011; 61: 69-90. http://dx.doi.org/10.3322/caac.20107

[2] MALONE CD, HANNON GJ. Small RNAs as guardians of the genome. Cell 2009; 136: 656-668. http://dx.doi.org/10.1016/ j.cell.2009.01.045

[3] MOAZED D. Small RNAs in transcriptional gene silencing and genome defence. Nature 2009; 457: 413-420. http://dx.doi. org/10.1038/nature 07756

[4] BROSNAN CA, VOINNET O. The long and the short of noncoding RNAs. Curr Opin Cell Biol 2009; 21: 416-425. http://dx.doi.org/10.1016/j.ceb.2009.04.001

[5] MATTICK JS. Non-coding RNAs: the architects of eukaryotic complexity. EMBO Rep 2001; 2: 986-991. http://dx.doi. org/10.1093/embo-reports/kve230 
[6] SCHOLER N, LANGER C, DOHNER H, BUSKE C, KUCHENBAUER F. Serum microRNAs as a novel class of biomarkers: a comprehensive review of the literature. Exp Hematol 2010; 38: 1126-1130. http://dx.doi.org/10.1016/ j.exphem.2010.10.004

[7] XIE Y, TODD NW, LIU Z, ZHAN M, FANG H et al. Altered miRNA expression in sputum for diagnosis of non-small cell lung cancer. Lung Cancer 2010; 67: 170-176. http://dx.doi. org/10.1016/j.lungcan.2009.04.004

[8] XING L, TODD NW, YU L, FANG H, JIANG F. Early detection of squamous cell lung cancer in sputum by a panel of microRNA markers. Mod Pathol 2010; 23: 1157-1164. http://dx.doi. org/10.1038/modpathol.2010.111

[9] GIBB EA, BROWN CJ, LAM WL. The functional role of long non-coding RNA in human carcinomas. Mol Cancer 2011; 10: 38. http://dx.doi.org/10.1186/1476-4598-10-38

[10] BERTONE P, STOLC V, ROYCE TE, ROZOWSKY JS, URBAN AE et al. Global identification of human transcribed sequences with genome tiling arrays. Science 2004; 306: 2242-2246. http://dx.doi.org/10.1126/science.1103388

[11] KAPRANOV P, DRENKOW J, CHENG J, LONG J, HELT G et al. Examples of the complex architecture of the human transcriptome revealed by RACE and high-density tiling arrays. Genome Res 2005; 15: 987-997. http://dx.doi.org/10.1101/ gr.3455305

[12] GIBB EA, BECKER-SANTOS DD, ENFIELD KS, GUILLAUD M, NIEKERK D et al. Aberrant Expression of Long Noncoding RNAs in Cervical Intraepithelial Neoplasia. Int J Gynecol Cancer 2012; 22: 1557-1563. http://dx.doi. org/10.1097/IGC.0b013e318272f2c9

[13] BENETATOS L, VARTHOLOMATOS G, HATZIMICHAEL E. MEG3 imprinted gene contribution in tumorigenesis. Int J Cancer 2011; 129: 773-779. http://dx.doi.org/10.1002/ijc.26052

[14] ZHOU Y, ZHANG X, KLIBANSKI A. MEG3 noncoding RNA: a tumor suppressor. J Mol Endocrinol 2012; 48: R45-R53. http://dx.doi.org/10.1530/JME-12-0008

[15] WANG P, REN Z, SUN P. Overexpression of the long non-coding RNA MEG3 impairs in vitro glioma cell proliferation. J Cell Biochem 2012; 113: 1868-1874. http://dx.doi. org/10.1002/jcb. 24055

[16] ZHANG X, GEJMAN R, MAHTA A, ZHONG Y, RICE KA et al. Maternally expressed gene 3 , an imprinted noncoding RNA gene, is associated with meningioma pathogenesis and progression. Cancer Res 2010; 70: 2350-2358. http://dx.doi. org/10.1158/0008-5472.CAN-09-3885

[17] BRACONI C, KOGURE T, VALERI N, HUANG N, NUOVO $\mathrm{G}$ et al. microRNA-29 can regulate expression of the long non-coding RNA gene MEG3 in hepatocellular cancer. Oncogene 2011; 30: 4750-4756. http://dx.doi.org/10.1038/ onc.2011.193
[18] BJORNSSON HT, BROWN LJ, FALLIN MD, RONGIONE MA, BIBIKOVA $\mathrm{M}$ et al. Epigenetic specificity of loss of imprinting of the IGF2 gene in Wilms tumors. J Natl Cancer Inst 2007; 99: 1270-1273. http://dx.doi.org/10.1093/jnci/ dim069

[19] BENETATOS L, DASOULA A, HATZIMICHAEL E, GEORGIOU I, SYRROU M, et al. Promoter hypermethylation of the MEG3 (DLK1/MEG3) imprinted gene in multiple myeloma. Clin Lymphoma Myeloma 2008; 8: 171-175. http://dx.doi. org/10.3816/CLM.2008.n.021

[20] TANG X, ZHANG Q, NISHITANI J, BROWN J, SHI S et al. Overexpression of human papillomavirus type 16 oncoproteins enhances hypoxia-inducible factor 1 alpha protein accumulation and vascular endothelial growth factor expression in human cervical carcinoma cells. Clin Cancer Res 2007; 13: 2568-2576. http://dx.doi.org/10.1158/1078-0432. CCR-06-2704

[21] ZHANG X, ZHOU Y, MEHTA KR, DANILA DC, SCOLAVINO $S$ et al. A pituitary-derived MEG3 isoform functions as a growth suppressor in tumor cells. J Clin Endocrinol Metab 2003; 88: 5119-5126. http://dx.doi.org/10.1210/jc.2003$\underline{030222}$

[22] HUARTE M, GUTTMAN M, FELDSER D, GARBER M, KOZIOL MJ et al. A large intergenic noncoding RNA induced by $\mathrm{p} 53$ mediates global gene repression in the p53 response. Cell 2010; 142: 409-419. http://dx.doi.org/10.1016/ j.cell.2010.06.040

[23] O'CONNELL MJ, WALWORTH NC, CARR AM. The G2phase DNA-damage checkpoint. Trends Cell Biol 2000; 10: 296-303. http://dx.doi.org/10.1016/S0962-8924(00)01773-6

[24] ANTTILA MA, KOSMA VM, HONGXIU J, PUOLAKKA J, JUHOLA $M$ et al. p21/WAF1 expression as related to p53, cell proliferation and prognosis in epithelial ovarian cancer. Br J Cancer 1999; 79: 1870-1878. http://dx.doi.org/10.1038/ sj.bjc. 6690298

[25] LIPOVICH L, JOHNSON R, LIN CY. MacroRNA underdogs in a microRNA world: evolutionary, regulatory, and biomedical significance of mammalian long non-protein-coding RNA. Biochim Biophys Acta 2010; 1799: 597-615.

[26] HUARTE M, RINN JL. Large non-coding RNAs: missing links in cancer? Hum Mol Genet 2010; 19: R152-R161.http:// dx.doi.org/10.1093/hmg/ddq353

[27] GORDON FE, NUTT CL, CHEUNSUCHON P, NAKAYAMA Y, PROVENCHER KA et al. Increased expression of angiogenic genes in the brains of mouse meg3-null embryos. Endocrinology 2010; 151: 2443-2452. http://dx.doi. org/10.1210/en.2009-1151

[28] HANAHAN D, WEINBERG RA. Hallmarks of cancer: the next generation. Cell 2011; 144: 646-674. http://dx.doi. org/10.1016/j.cell.2011.02.013 